\title{
The Crack Propagation Trend Analysis in Ceramic Rolling Element Bearing considering Initial Crack Angle and Contact Load Effect
}

\author{
Zhe Yuan $\left(\mathbb{D},{ }^{1}\right.$ Bohan Wang, ${ }^{1}$ Chao Liu $\mathbb{D}^{2},{ }^{2}$ Zhan Wang $\left(\mathbb{D},{ }^{1}\right.$ Xiaochen Zhang $\left(\mathbb{D},{ }^{1}\right.$ \\ and Yu Zhang (D) \\ ${ }^{1}$ School of Mechanical Engineering, Shenyang Jianzhu University, Shenyang 110168, China \\ ${ }^{2}$ State Key Laboratory of Ultra-Precision Machining Technology, Department of Industrial and Systems Engineering, \\ The Hong Kong Polytechnic University, Hung Hom, Kowloon, Hong Kong 999077, China
}

Correspondence should be addressed to Yu Zhang; yeahzhangyu@126.com

Received 23 February 2021; Accepted 14 July 2021; Published 30 July 2021

Academic Editor: Marco Cocconcelli

Copyright (c) 2021 Zhe Yuan et al. This is an open access article distributed under the Creative Commons Attribution License, which permits unrestricted use, distribution, and reproduction in any medium, provided the original work is properly cited.

Silicon nitride ceramic bearings are widely used for their excellent performance. However, due to their special manufacturing method, cracks will occur on ceramic ball surface, and this initial surface crack will propagate under the action of cyclic stress, which will lead to material spalling. This will greatly limit its service life in practical applications, especially under heavy load at high speed. Therefore, it is necessary to study the surface crack propagation of silicon nitride ceramic bearings. In this paper, the effect of initial crack angle and contact load on crack growth is analysed by the finite element method (FEM). A three-dimensional finite element model of a silicon nitride bearing ball containing an initial crack is created by the FEM. The cracks are initially classified based on the angle between the crack and the bearing ball surface, and the location of the most dangerous load for each type of crack is known by theoretical analysis. The stress intensity factors (SIFs) are calculated for the crack front to investigate the effect of load position on crack growth. Subsequently, the SIFs are calculated for each type of crack angle subdivided again to investigate the effect of crack angle on crack propagation.

\section{Introduction}

Due to the advancement of modern technology and the development of industrial production, silicon nitride ceramic bearings have been used widely because of their wear resistance and corrosion resistance, and it can work at high speed. It can be used in some special conditions, such as extreme temperature and corrosive environment. Because of the special sintering process of making ceramics, cracks will occur on the surface of ceramic balls with different shapes and random locations, and cracks will propagate as the bearing works, leading to spalling and rolling contact fatigue failure. Although there has been a lot of work done by related scholars, the failure mechanism of silicon nitride ceramic bearing balls with surface cracks has not been well understood, so it is necessary to study the propagation mechanism of surface cracks to understand ceramic bearing rolling contact fatigue failure.

The mechanism of crack initiation and propagation on bearings has been studied by many scholars. Crack initiation and its propagation mechanisms on metal bearing have been confirmed that cracks are mainly caused by surface cracks and subsurface cracks. Surface cracks are mainly caused by machining tool marks and pits caused by shedding of inclusions; correspondingly, subsurface cracks are mainly caused by internal nonmetallic inclusions (such as $\mathrm{Al}, \mathrm{Ca}, \mathrm{Si}$, and $\mathrm{Mg}$ oxides). Fatigue cracks occur throughout the fatigue life of the bearing. Initiation accounts for more than $94.1 \%$ $[1,2]$. For ceramic bearings, Shi et al. [3] proposed a nonlinear dynamic model considering the effect of crack spalling; it can be used to analyse the vibration response of all-ceramic bearings with cracks and outer ring spalling. Khader et al. [4] proposed that the formation and propagation of the crack are more likely to occur in locations withstanding alternating load based on Paris law.

According to Zhou [5], the main reason for the failure of ceramic bearings is crack propagation to spalling. Wang and Hadfield [6] proposed that the C-crack failure is related to the crack location in the contact path. Fatigue failure only 
occurs in a few crack locations/orientations. Some studies present a series of finite element model to study the initiation and propagation process of the crack and the final failure mode in rolling contact fatigue. A two-dimensional finite element model was created in which the grain boundaries were modeled directly with the cohesive zone approach, and in agreement with the expected results already presented, the introduction of material defects would reduce the basic rated life [7]. A damage mechanics-based Voronoi finite element model (VFEM) is developed and used to investigate the effects of surface defects in elastohydrodynamic lubricated line contacts. In this way, the model is used to simulate microcrack initiation, propagation stages, and fatigue spall. The results show that the location and pattern of spalling caused by dents are consistent with experimental observations [8]. For experimental work, Zhou et al. [9] have conducted research on the failure of silicon nitride ceramic balls, including the mechanism of fatigue dynamic failure, influencing factors of fatigue failure, and failure probability model; they proposed that the subsurface cracks are mainly caused by material volume defects, and the critical stress for bearing ball failure is the maximum principal tensile stress in the process of spalling formation. Based on this, a tensile stress-life model that is more suitable for the prediction of the rolling contact fatigue life of ceramic balls is proposed. The cavitation-rolling contact fatigue condition of the material system is evaluated by integrating rolling contact and cavitation testing into one test method [10]. Some scholars have also studied the influencing factors of bearing failure. Based on the uncertainty analysis and parametric studies, the failure probability of surface cracks in silicon nitride ball bearings rolling contact fatigue is estimated by Pattabhiraman et al. [11]; the study shows that the most significant method to make the probability of failure decrease is to reduce the maximum crack size and increase the fatigue threshold. In hybrid bearings, slight wear, higher plastic deformation, and lower boundary friction can help to improve the dent response of the bearing in rolling contact and reduce local stress concentrations and gradients through the accumulation of excessive rolling cycles [12].

In general, people use Paris law to calculate the growth rate of bearing surface cracks; furthermore, the bearing life can be obtained through the $\mathrm{N}$-a curve. Deng et al. [13] investigated the role of material defects on the crack initiation under rolling contact fatigue and considered the effects of the moment,the radical load, and other factors on SIF$s$,crack growth rates and crack initiation. Moreover, they proposed a simulated model to study the effect of the crack inclined angle and the hardness of inclusions on fatigue damage in bearings. They have confirmed that the shear mode plays an important role in the crack initiation and the other modes are subordinate. Xu et al. $[14,15]$ analysed and predicted the life of ball bearings based on nonlinear dynamics and proposed the concept of the critical surface to improve the Paris fatigue life prediction model. In addition, $\mathrm{Xu}$ et al. [16] based on the trend that the root mean square of the eigenmode function of the fault characteristic frequency is consistent with the defect diameter, two improved Paris models are proposed, which can predict the remaining fatigue life of the bearing online without disturbing the normal operation of the machine. For oxide ceramics, the SIFs will change under the influence of phase transformation toughening. In order to calculate the stress intensity factor more accurately, Wang et al. [17] proposed a new strength and yield criterion for oxide ceramics.

Based on the above analysis, the crack growth rate calculated by SIFs has a great influence on the bearing life assessment. Although the calculation of the SIFs has been continuously explored by relevant scholars, it is still difficult to determine the SIFs because they are related to the crack geometry, load position and loading mode, temperature, etc. $[6,18]$. Therefore, some 2D crack models have been established to clarify the influence of crack propagation on rolling contact fatigue [19, 20]. Wang and Hadfield [21] proposed the surface crack geometry is very significant for the analysis of the fracture mechanism. However, the crack is a three-dimensional shape in the ceramic bearing ball; the two-dimensional crack model cannot reflect the true propagation state of the whole crack. Related scholars have also established a three-dimensional crack growth model [22-25]. More advanced FEM-based simulations using the R-curve approach for dry nonmoving monotonically and cyclically loaded contacts focused on the principal tensile stresses [26]. Nazir et al. [27] established a semielliptical three-dimensional crack model to calculate the fatigue failure probability of c-shaped cracks on the surface of silicon nitride ball bearing components under rolling contact fatigue. However, SIFs are related to crack shape, size, loading mode, etc. So, it is not possible to make simple assumptions in crack geometry and loading mode to reflect the real situation. To simulate the real crack shape, this paper uses the finite element method to establish a three-dimensional crack model to clarify the effect of the initial state of the crack on the surface stress distribution of the crack.

The initial state of the crack includes the crack depth, the crack geometry, and the initial angle of the crack. The initial angle of the crack is different, and the stress distribution at the crack tip is also different. Therefore, the effect of the initial crack angle on crack propagation is also worth paying attention to. Hua et al. [28] proved that surface cracks on metal bearing raceway typically propagate at an angle of about $15^{\circ}-45^{\circ}$ and can then either stop, continue growing, or branch towards the surface, causing fatigue pitting phenomena.

As the bearing works, the position of the bearing ball under load also changes continuously. For the bearing ball with surface cracks, the crack propagation will also change with the change of the load position. However, previous studies did not analyse the mechanism of the crack propagation of ceramic bearing balls based on the relative position of the crack and the load and the initial angle of the crack. In this paper, we initially classify the cracks according to the different initial angles between the cracks and the bearing ball surface and also consider the effect of the changing load position on the cracks at different angles, and the forces of the cracks are analysed to obtain the most dangerous locations for different types of cracks. At the same time, the initial angles of different types of cracks are 
subdivided again to clarify the influence of initial crack angles on crack propagation. First, a realistic three-dimensional finite element model of the bearing ball containing a surface crack is established. Second, the model is loaded to find out the load position that has the greatest influence on crack propagation. Then, the crack propagation under different conditions was predicted. Finally, cracks of different initial angles are inserted into the ceramic bearing ball model to calculate the SIFs of the crack front. The results are helpful for better understanding the effect of surface cracks on rolling contact fatigue of the silicon nitride ceramic bearings.

\section{Calculation of Stress Intensity Factors}

According to the Hertzian contact theory, the contact mode of the bearing ball and the bearing raceway is Hertzian contact. On the surface of ceramic bearing balls, there are Hertzian contact stress $p(x, y)$ and tangential traction $q(x, y)$ within the contact region. The Hertzian contact stress and tangential traction can be described as

$$
\begin{aligned}
& p(x, y)=p_{0} \sqrt{1-\frac{x^{2}+y^{2}}{\lambda^{2}}}, \\
& q(x, y)=f p(x, y),
\end{aligned}
$$

where $p_{0}$ is the maximum normal pressure, $\lambda$ is the radius of the contact circle, $f$ is the friction coefficient, and when the contact circle passes over the ring crack from left to right, define $f>0$; on the contrary, $f<0 . \lambda$ and $p_{0}$ can be given by

$$
\begin{aligned}
p_{0} & =\frac{3 P}{2 \pi \lambda^{2}}, \\
\lambda & =\left(\frac{3 P}{4} \times \frac{\left(\left(1-v_{1}^{2}\right) / E_{1}\right)+\left(\left(1-v_{2}^{2}\right) / E_{2}\right)}{\left(1 / R_{1}\right)+\left(1 / R_{2}\right)}\right)^{1 / 3},
\end{aligned}
$$

where $P$ is the applied load on the silicon nitride ceramic bearing ball, $v_{1}$ and $v_{2}, E_{1}$ and $E_{2}$ are Poisson's ratio and Young's modulus of the bearing ball and the bearing raceway, respectively. $R_{1}$ and $R_{2}$ are the radius of the bearing ball and the bearing raceway, respectively.

In structural materials, there are three main ways in which cracks propagate under the action of external forces, as shown in Figure 1. Mode I, also known as "the opening mode," is mainly caused by normal stress, with the displacement of the crack surface perpendicular to the crack plane. In-plane shear produces mode II, also called "the sliding mode." Out-of-plane shear produces mode III or "the tearing mode," where the crack surface displacement is in the plane of the crack and parallel to the edge of the crack on the leading surface of the crack. $K_{\mathrm{I}}, K_{\mathrm{II}}$, and $K_{\mathrm{III}}$ are the SIFs in mode I, mode II, and mode III, respectively.

In the process of bearing working, the surface crack is affected by Hertzian contact stress if there is a surface crack on the ceramic bearing ball. When the change amplitude of the stress intensity factor $\Delta K$ generated by Hertzian contact stress exceeds the threshold value $\Delta K_{\mathrm{th}}$,
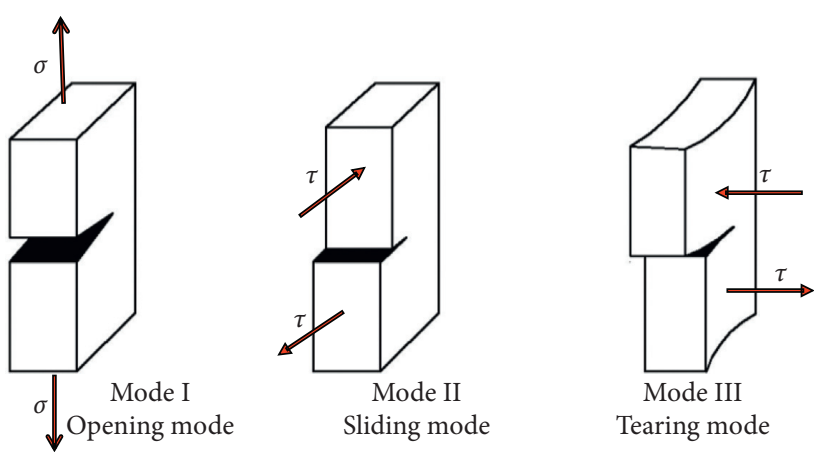

Figure 1: Basic crack model diagram.

the crack will propagate. $\Delta K$ can be expressed by the following equation:

$$
\Delta K=K_{\max }-K_{\min } .
$$

According to reference [13], when Hertzian contact stress and friction do not act on the crack, there exists $K_{\min }$, which has the value 0 . So, $\Delta K$ is determined by $K_{\max }$. During the bearing working, cracks propagate in a mixed-mode under the action of Hertzian contact stress and friction which means $K_{\mathrm{I}}, K_{\mathrm{II}}$, and $K_{\text {III }}$ exist simultaneously during the process of crack propagation; $\Delta K$ can be given by the following equation:

$$
\Delta K=K_{\max }-0=K_{\text {eff }}=\left[\left(K_{\mathrm{I}}+\left|K_{\text {III }}\right|\right)^{2}+2 K_{\text {II }}^{2}\right]^{1 / 2} .
$$

In order to judge whether the crack will grow, SIFs need to be calculated. In this paper, the crack opening displacement (COD) method is used to calculate SIFs. SIFs of mode I, mode II, and mode III are calculated using the following equations [26]:

$$
\begin{aligned}
K_{\mathrm{I}} & =\frac{E}{4\left(1-v^{2}\right)} \sqrt{\frac{\pi}{2 r}}\left(a_{1}-a_{2}\right), \\
K_{\mathrm{II}} & =\frac{E}{4\left(1-v^{2}\right)} \sqrt{\frac{\pi}{2 r}}\left(b_{1}-b_{2}\right), \\
K_{\mathrm{III}} & =\frac{E}{4\left(1-v^{2}\right)} \sqrt{\frac{\pi}{2 r}}\left(c_{1}-c_{2}\right) .
\end{aligned}
$$

The symbol $a$ is the displacement that is perpendicular to the ring crack surface, $b$ is the displacement that is perpendicular to the crack tip direction, $c$ is the tangent line that is touching the crack tip and $r$ represents length between the crack tip and the point from where $a, b$, and $c$ are measured. " 1 " and " 2 " are the points in time at which corresponding $a, b$, and $c$ displacement components are evaluated. The geometric relationship of the parameters is shown in Figure 2.

\section{The Effect of the Load Position and Initial Crack Angle}

During the rotation of the bearing, the Hertzian contact load acting on the bearing ball is cyclically loaded. We assume that the direction of load movement is clockwise. The 


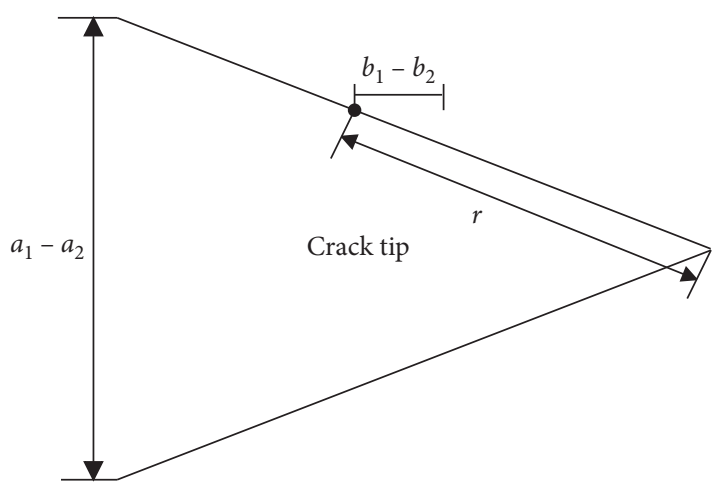

FIGURE 2: Schematic showing the crack-tip opening displacement.

loading mode of the ceramic bearing ball can be simplified, as the contact stress region continuously rolls on the surface of the bearing ball. Since the location, initial angle, and depth of the cracks generated during the preparation of silicon nitride ceramic bearing balls are randomly distributed, cracks may exist on the surface, near the surface, or inside the ceramic ball, and under Hertzian contact stresses and frictional forces, the cracks propagate leading to spalling. In this paper, we choose surface cracks to study.

The Hertzian stress area keeps approaching the crack until it presses on the crack and then gradually moves away when the bearing ball rolls in the bearing. In this process, with the continuous rolling of the bearing ball, the influence of the Hertzian contact stress on the crack is also changing. Obviously, the initial crack angle is different, and the Hertzian contact stress has a different effect on the crack. Therefore, three cracks with different angles (crack I, crack II, and crack III at acute, right, and obtuse angles to the positive $X$-axis, respectively) are inserted in the ceramic bearing ball, respectively. The locations of dangerous loads and crack propagation mechanisms for cracks at different initial angles are analysed as follows.

Due to the effect of the frictional force on crack propagation is different when the initial angle between the crack and the positive $X$-axis is the acute angle (crack I), right angle (crack II), or obtuse angle (crack III), so the propagation mechanism of these three types of surface cracks is investigated separately. The loading process of the ceramic bearing ball is shown in Figure 3 .

To make the analysis simplified, the crack geometry and the Hertzian contact stress in the three-dimensional model are shown in Figure 4, where a surface loading traverses a surface crack, repeatedly. $d$ is the distance between the deepest part of the crack and the surface of the model, which is the depth of the crack, $\alpha$ is the angle between the crack and the positive $X$-axis, $\theta$ is the crack arc angle, and $R$ is the crack radius.

Figure 5 shows the crack-tip opening displacement of cracks I and II in stages. In stage 1, when the load is far from the crack, there is no effect on crack propagation. The load gradually approached the crack and began to affect the crack. The closer the distance between the load and the crack, the greater the $K_{\mathrm{I}}$, until stage 2; $K_{\mathrm{I}}$ reaches the maximum when the crack is at the load boundary position. Then, $K_{\mathrm{I}}$ gradually

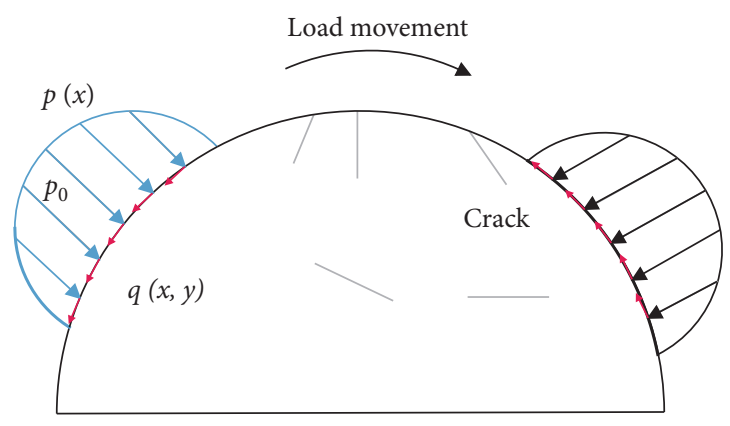

FIGURE 3: The loading process of the ceramic bearing ball.

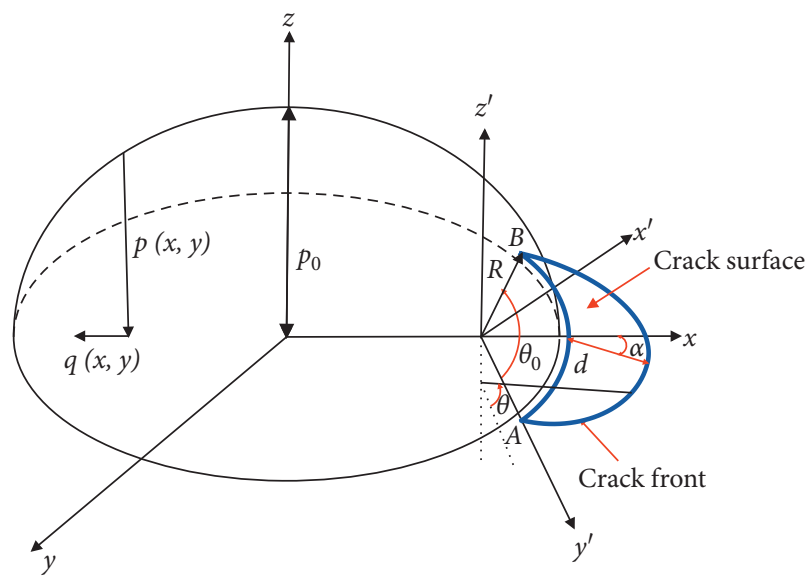

FIgURE 4: Crack and Hertzian contact stress model.

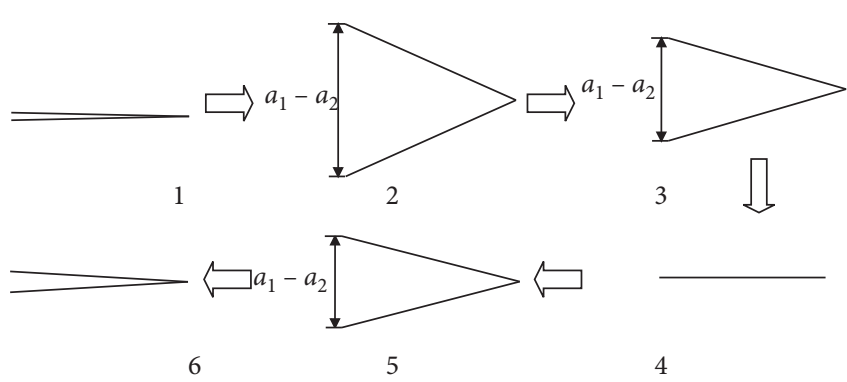

FIGURE 5: Schematic showing the crack-tip opening displacement in stage-wise fashion for cracks I and II.

decreases until the load is at the top of the crack, the crack is closed, and $K_{\mathrm{I}}$ is 0 at stage 4 . With the continuous movement of the load, the crack opens again under the action of tensile stress, but at this time, due to the influence of initial crack angle and friction, the opening displacement of the crack is not as large as in stage 2 , so the $K_{\mathrm{I}}$ at this stage is smaller than that in stage 2 . Finally, the load gradually moves away from the crack, and the effect on the crack decreases until it does not work.

When the crack is at an acute angle with the positive direction of the $X$-axis, the most dangerous location for crack growth is shown in Figure 6(a). With the movement of the load, when the Hertzian contact load moves to the position shown in Figure 6(a), the frictional force imposes tensile stress causing an opening displacement on the crack 


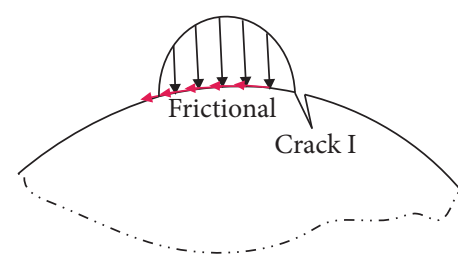

(a)

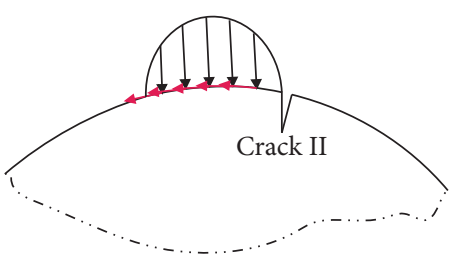

(b)

Figure 6: Stress process on crack surface: (a) crack I; (b) crack II.

and the Hertzian contact load exerts tensile stress on the crack which causes an opening displacement and compressive stress on the crack which causes a slipping displacement, and the displacement due to the frictional force and the Hertzian contact stress is maximum at this position. Therefore, there will be slipping and the opening between the crack faces, and the crack propagates mainly in mode I and mode II. In summary, in the case where the crack is at an acute angle to the positive direction of the $X$-axis, the crack propagates mainly in mode I and mode II; $K_{\mathrm{I}}$ and $K_{\mathrm{II}}$ have a greater effect on the crack propagation.

When the crack is at a right angle to the $X$-axis, the most dangerous position for crack propagation is shown in Figure $6(\mathrm{~b})$. With the movement of the load, when the Hertzian contact load moves to the position shown in Figure 6(b), under the action of friction, the crack will open; however, at this time, the Hertzian contact stress will not open the crack, but will only cause the crack to slip. Thus, at this point for crack II, there is a small crack opening and a very large slip. In summary, in the case where the crack is at a right angle to the $X$-axis, the crack grows in mode I and mode II; because the friction coefficient acting on the bearing ball is 0.05 , the friction force is small, so the influence of $K_{\mathrm{I}}$ on crack growth is also small, and the crack propagation in this case is mainly based on the slip. $K_{\mathrm{I}}$ and $K_{\mathrm{II}}$ exist at the same time, $K_{\mathrm{II}}$ is much larger than $K_{\mathrm{I}}$.

The crack-tip opening displacement of crack III is shown in Figure 7. For crack III, in stage 1, when the load is far from the crack, it has no effect on crack propagation. Then, the load gradually approached the crack and began to affect the crack. However, due to the effect of the initial crack angle, the Hertzian contact stress always exerts pressure on the crack, and the crack is in a closed state until the load boundary rolls over the crack and the crack begins to open. With the continuous movement of the load, the crack opening displacement gradually increases. When the Hertzian contact load boundary just coincides with arc $A B$, the crack opening displacement reaches the maximum and $K_{\mathrm{I}}$ is the maximum, the crack is in stage 3. Finally, the load gradually moves away from the crack, and the effect on the crack decreases until it does not work.

When the crack is at an obtuse angle with the positive direction of the $X$-axis, the most dangerous position of the crack propagation is shown in Figure 8. With the movement of the load, when the Hertzian contact load moves to the position shown in Figure 8, the friction force exerts pressure stress on the crack to make the crack close; however, the Hertzian contact load exerts tensile stress on the crack to

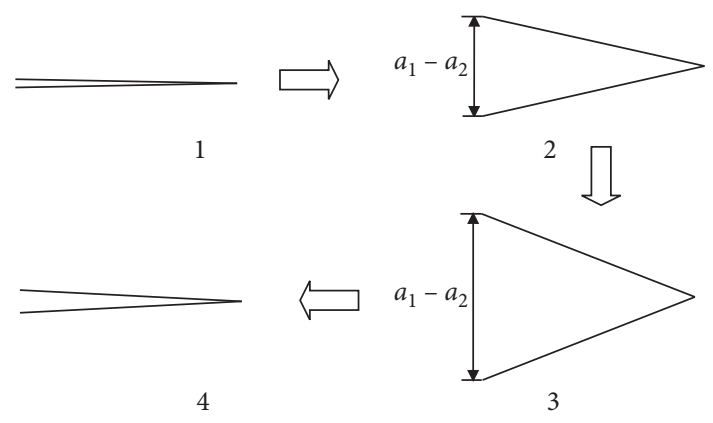

FIgURE 7: Schematic showing the crack-tip opening displacement in stage-wise fashion for crack III.

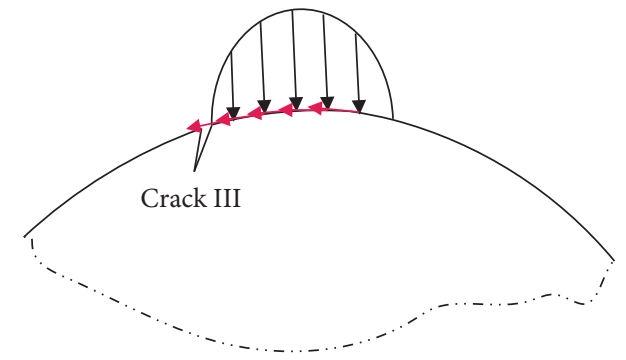

Figure 8: Stress process on crack surface for crack III.

make the crack open and pressure stress to make the crack slip and the tensile stress exerted by the Hertzian contact load is much larger than the compressive stress exerted by the friction force; therefore, the crack will open and slip. So, there is both slipping and the opening between the crack surfaces and the crack grows in mode I and mode II. In summary, in the case where the crack is at an obtuse angle to the positive direction of the $X$-axis, the crack propagates in both the open mode and the slip mode, both $K_{\mathrm{I}}$ and $K_{\mathrm{II}}$ exist in this case.

According to the above analysis, the initial crack angle is different, and the location of the load that makes the crack in the most dangerous state is different. The crack is most dangerous when the Hertzian contact load boundary just coincides with arc $\mathrm{AB}$ and both apply tensile stress to it, i.e., the state (a) in Figure 6. At this time, the Hertzian contact stress has the greatest impact on the crack and the crack is most likely to propagate. The crack is most likely to occur with low-stress brittle cracking.

Because the initial crack angle is different, the load has a different effect on crack growth. Therefore, the initial angles of crack I and crack III have refined again, the influence of 
the initial crack angle on crack growth is further discussed. The schematic diagram of the initial crack angle distribution is shown in Figure 9. Geometrically, for crack I, the smaller the initial crack angle, the closer the crack front is to the surface of the bearing ball, and the opposite of crack III. This leads to the difference in the distance between the maximum point of the crack front and the spherical surface and the different stress distribution at the crack front. According to Vieillard [29], the smaller the defect distance under the surface, the greater the principal stress, so the closer to the crack on the surface of the bearing ball, the greater the $K_{\mathrm{I}}$.

\section{Result and Discussion}

4.1. Validation of Numerical Model. In order to verify the validity of the model, we inserted cracks with the same crack parameters as those in reference [21] into the model (crack radius is $0.21 \mathrm{~mm}$, crack depth is $0.051 \mathrm{~mm}$, the angle of the ring crack arc $\mathrm{AB}$ is $90^{\circ}$, and the initial crack angle is $51^{\circ}$ ) and calculated SIFs of the crack and verified them. Figure 10 shows the SIFs when the crack is under Hertzian contact stress with $5.58 \mathrm{GPa}$, a Hertzian contact radius with $0.21 \mathrm{~mm}$, and a friction force with a friction coefficient of 0.05 . It can be concluded that the average relative error of the calculated stress intensity factor with that in reference [21] is $7.4 \%$. The calculated results in this paper are in good agreement with those in reference [21]. Therefore, by comparing the stress intensity factors between the numerical analysis and reference [21], it can be proved that the numerical analysis is reliable.

In addition, we also studied the stress distribution of the crack. The stress distribution is shown in Figure 11(a), the darker part is the surface of the bearing ball, and the brighter part is the inside of the bearing ball. The crack is located at the boundary of the Hertzian contact stress zone. It can be seen from Figure 11(b) that under the action of Hertzian contact stress and friction, there is a stress concentration at the end and crack front.

4.2. Analysis of Crack Growth. The three cracks described in Section 2 were loaded to verify that for different cracks, making the crack at the most dangerous load position. The cracks are loaded, as shown in Figure 12, friction always points to the left, and the left end of the Hertzian contact load starts to move to the right from this position and keeps approaching the beginning of the crack. For each type of crack, the stress intensity factors at four positions $P_{1}, P_{2}, P_{3}$, and $P_{4}$ are selected for calculation to illustrate the effect of load position changes on the growth of different types of cracks. According to the analysis in Section 3, when the Hertzian contact load and arc AB just overlap, the crack is in a dangerous position, and in order to avoid the load being too far away from the crack, with less influence on the crack propagation, the position $0.08 \mathrm{~mm}$ away from the most dangerous load position is selected, so $P_{1}$ is taken as the $X$ axis 0 point, then $P_{2}$ is $x=0.08 \mathrm{~mm}, P_{3}$ is $x=0.5 \mathrm{~mm}$, and $P_{4}$ is $x=0.58 \mathrm{~mm}$. The geometry of the inserted crack and the relative positional relationship between the crack and the

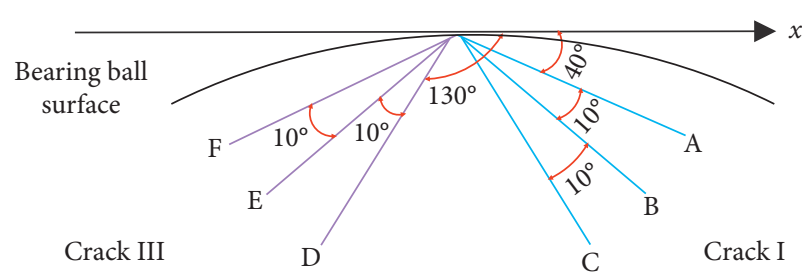

FIgURE 9: Crack angle distribution diagram.

model is shown in Figure 13; in this paper, $d$ is $0.05 \mathrm{~mm}, \theta$ is $90^{\circ}$, and $R$ is $0.21 \mathrm{~mm}$.

As shown in Figure 14(a), when the load position is $0.5 \mathrm{~mm}$, the equivalent stress intensity factor reaches the maximum. The Hertzian contact load region boundary and arc $\mathrm{AB}$ just overlap at this position, the crack is just at the boundary of the Hertzian contact load region and the Hertzian contact load exerts tensile stress to open the crack and a pressure to slip the crack, and the frictional force on the crack exerts tensile stress at this moment, so opening and slipping occur between the crack surfaces. The stress intensity factor at this location is calculated, as shown in Figure $14(\mathrm{~b}), K_{\mathrm{I}}$ and $K_{\mathrm{II}}$ play a dominant role on $K_{\text {eff. }}$ The crack propagation direction follows the mechanical energy release rate criterion, and according to Zhong [30], for cracks under tensile stress, the direction of crack propagation is perpendicular to the direction of the main tensile stress; for cracks under torsional load, its propagation direction is parallel to the direction of shear stress. So, it is predicted that the crack will grow to the lower right for the crack I, the crack will propagate deeper along the current direction for cracks II and III. The expansion propagation direction for crack I is predicted, as shown in Figures 14(c) and $14(d)$.

Figure 15(a) shows the calculation results of the equivalent stress intensity factor of crack II under different position loads. For crack II, $K_{\text {eff }}$ also reaches the maximum when the load position is $0.5 \mathrm{~mm}$. At this time, the Hertzian contact stress region coincides with arc $\mathrm{AB}$. However, at this time, the Hertzian contact stress only applies pressure to the crack, because the initial crack angle is different. Only the friction force exerts a load on the crack which causes the crack to generate a displacement in mode I. Therefore, when crack II is in a dangerous position, crack propagation is mainly due to slip between the crack faces, and crack openings also appeared, but with a smaller amplitude. The stress intensity factor at this location is shown in Figure $15(\mathrm{~b}), K_{\text {II }}$ plays a dominant role on $K_{\text {eff. }}$ The propagation for crack II is predicted, as shown in Figures 15(c) and $15(\mathrm{~d})$

Figure 16(a) shows the calculation results of $K_{\text {eff }}$ of crack III under different position loads. For crack III, $K_{\text {eff }}$ reaches the maximum when the load position is $0.08 \mathrm{~mm}$. Although the frictional force closes the crack at this location, the Hertzian contact stress exerts a pressure to slip the crack and tensile stress to open the crack and is much greater than the frictional force, so the crack is still under tension. In summary, when crack III is in a dangerous position, the main contributors to crack propagation are $K_{\mathrm{I}}$ and $K_{\mathrm{II}}$. This 


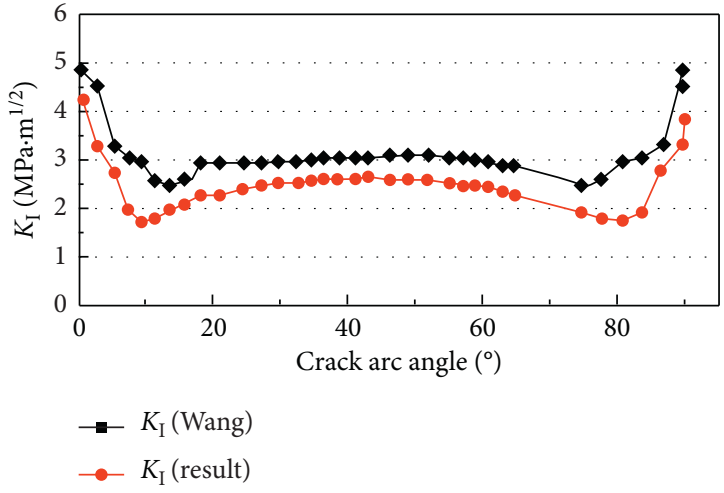

(a)

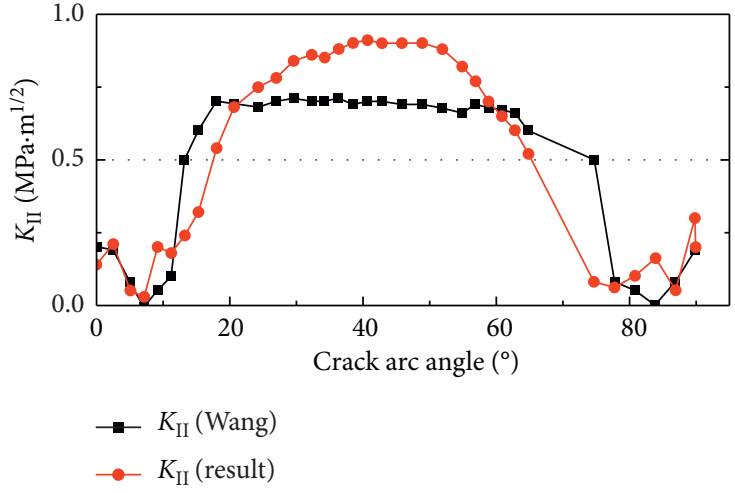

(b)

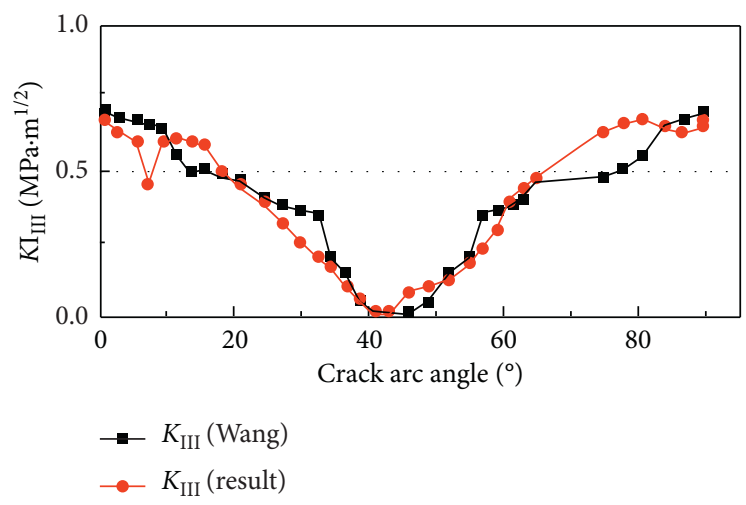

(c)

FIGURE 10: Comparison of calculation results of SIFs: (a) $K_{\mathrm{I}}$. (b) $K_{\mathrm{II}}$ (c) $K_{\mathrm{III}}$.

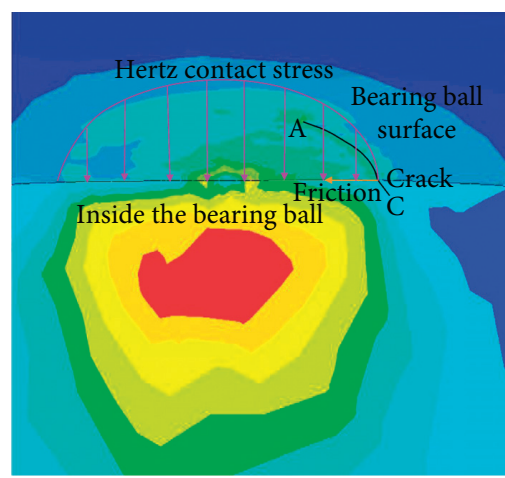

(a)

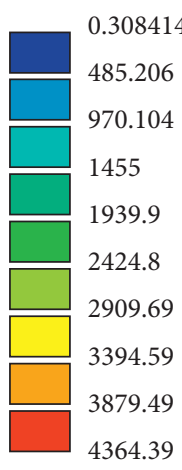

4364.39

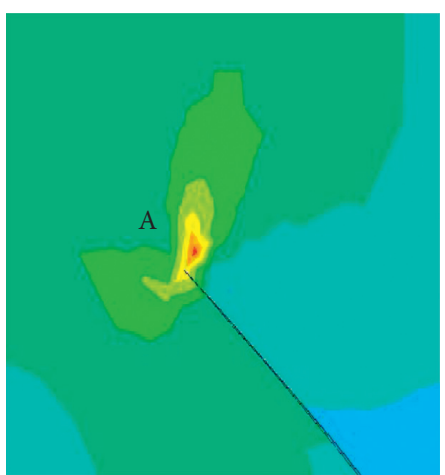

(b)

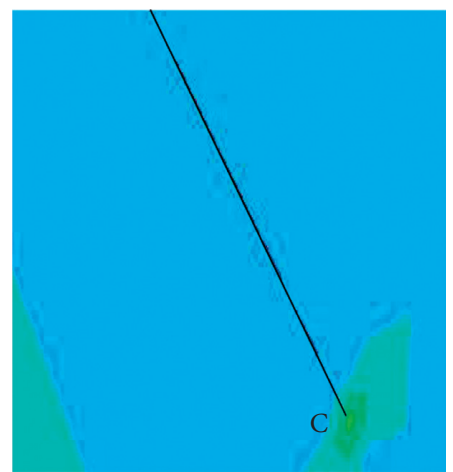

(c)

Figure 11: Stress distribution diagram of ceramic ball with crack: (a) the stress contour of the ceramic bearing ball; (b) stress concentration of point $\mathrm{A}$; (c) stress concentration of point $\mathrm{C}$ on the front of crack.

result is consistent with the distribution of the stress intensity factor when crack III is in this position, as shown in Figure 16(b).

From the analysis for the crack I and II mentioned above, it can be seen that when the load is in the same position, the initial crack angle is different and the stress distribution of the crack is also different. It can be presumed that the initial crack angle also plays an important role in crack propagation. Therefore, we modified the initial crack angle $\alpha$ for both types of crack I and crack III with the purpose to verify the effect of the initial crack angle on crack growth. The detailed parameters of the cracks are shown in Table 1.

As shown in Figures 17 and 18, after calculation, it is found that the equivalent stress intensity factor of crack I reaches the maximum when the initial angle between the crack and the positive direction of the $X$-axis is 60 degrees, and that of crack III is 130 degrees. In order to explore the reasons, we calculated $K_{\mathrm{I}}$ and $K_{\mathrm{II}}$ for different initial angles. The results show that for crack I and crack III, the reason for maximizing the equivalent stress intensity factor of the crack 


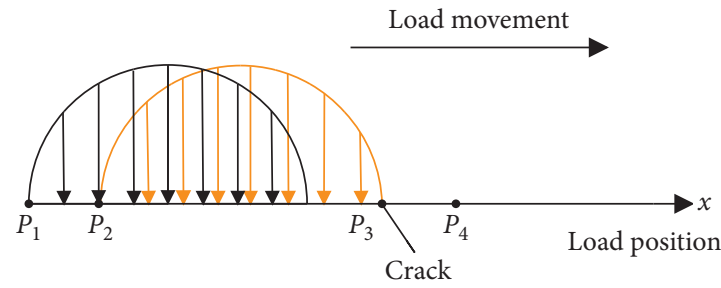

Figure 12: Relative position of crack and load.

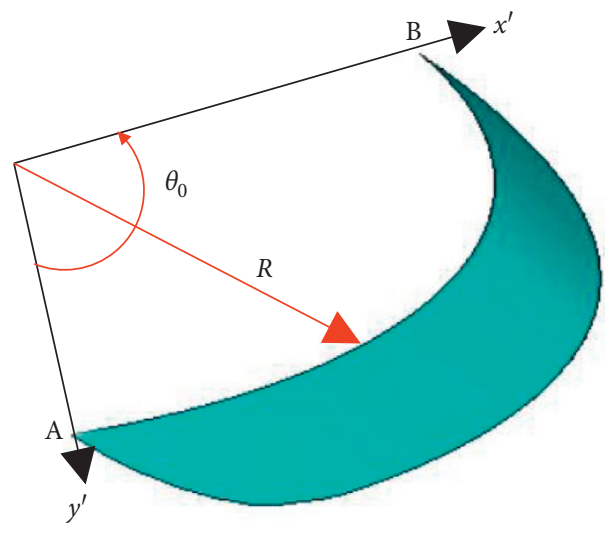

(a)

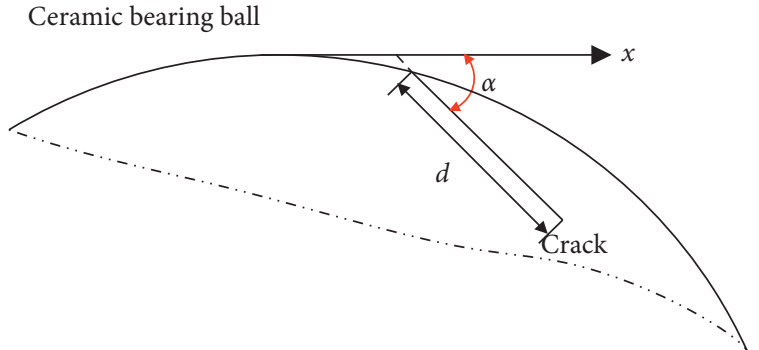

(b)

Figure 13: Crack schematic: (a) crack geometry; (b) the position of the crack.

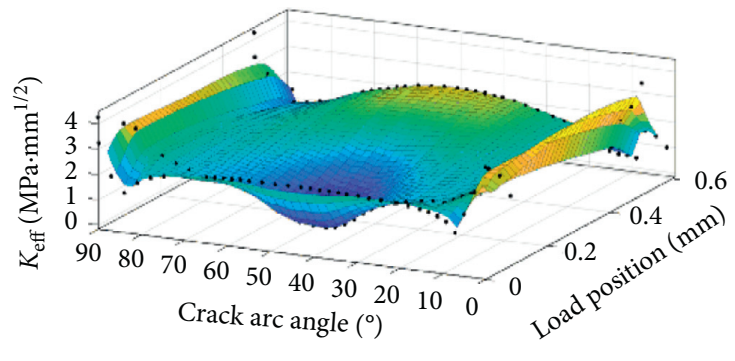

- $z$ vs. $x, y$

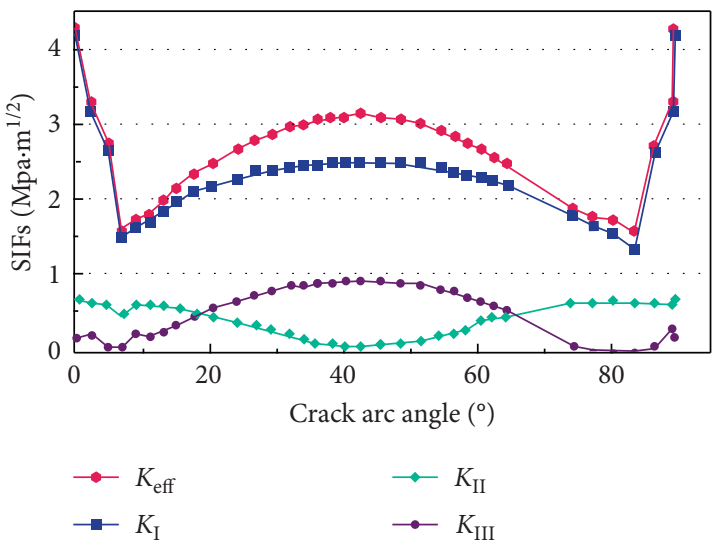

(b)

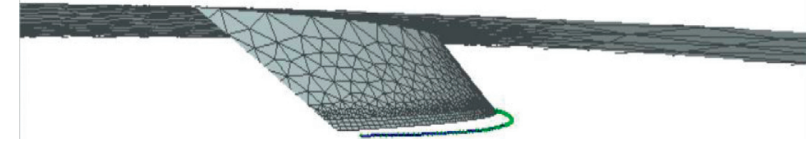

Ceramic ball surface Crack surface

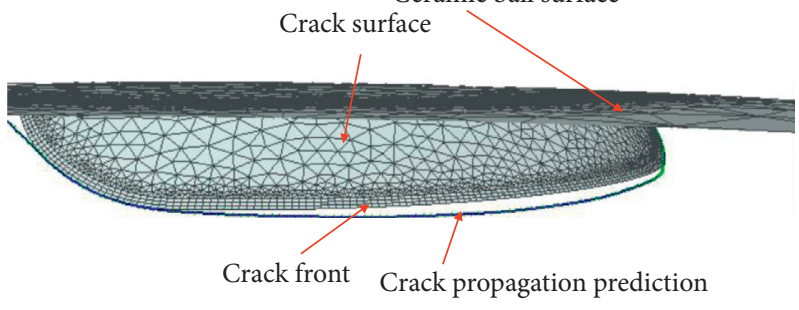

(c)

(d)

FIGURE 14: Related results for crack I: (a) $K_{\text {eff }}$ at different positions; (b) calculation of the SIFs when the load position is $0.08 \mathrm{~mm}$; (c) front view of crack propagation; (d) side view of crack propagation. 


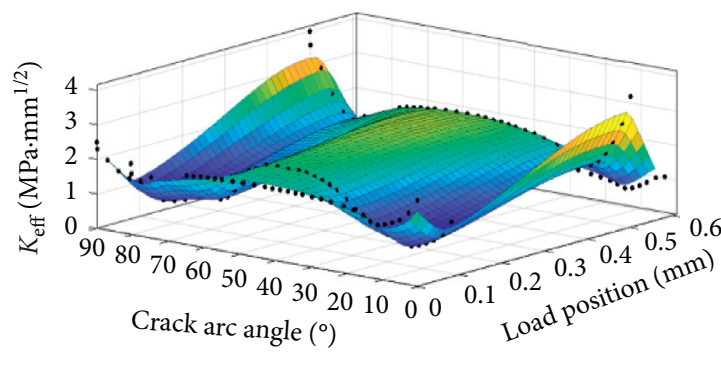

- $z$ vs. $x, y$

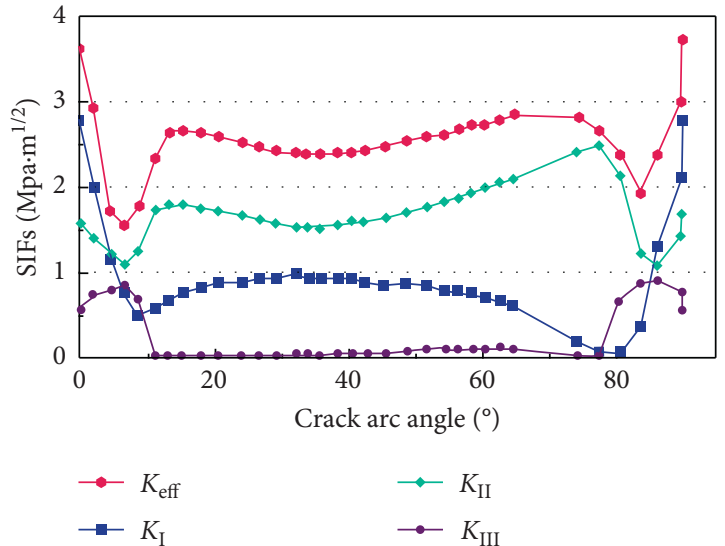

(b)

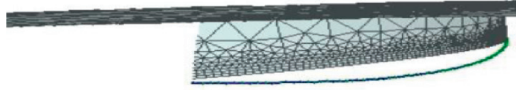

(d)

FIGURE 15: Related results for crack II: (a) $K_{\text {eff }}$ at different positions; (b) calculation of the SIFs when the load position is $0.08 \mathrm{~mm}$; (c) front view of crack propagation; (d) side view of crack propagation.

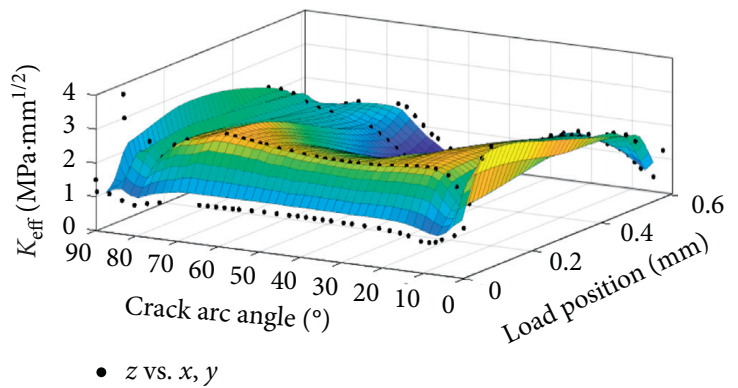

(a)

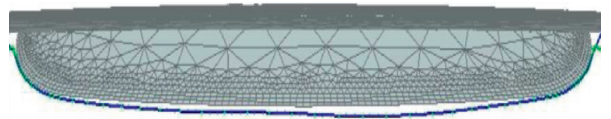

(c)

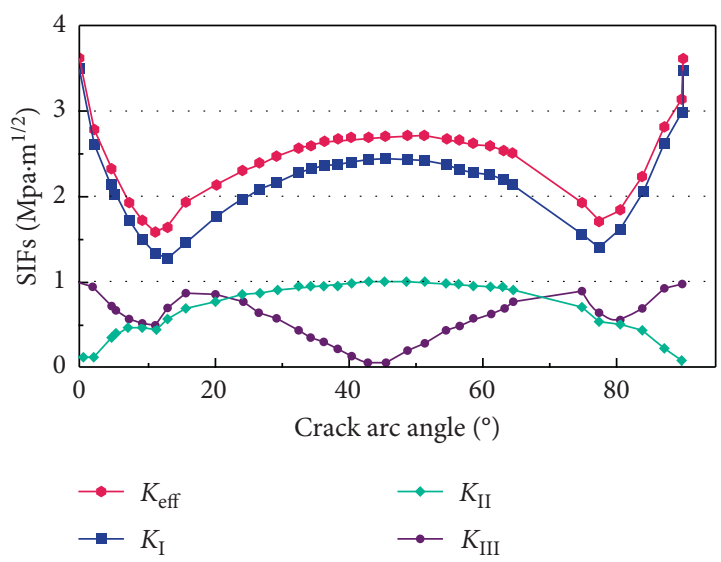

(b)

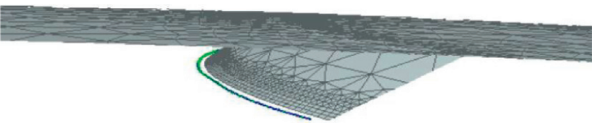

(d)

FIgURE 16: Related results for crack III: (a) $K_{\text {eff }}$ at different positions; (b) calculation of the SIFs when the load position is $0.5 \mathrm{~mm}$; (c) front view of crack propagation; (d) side view of crack propagation.

TABLE 1: Crack size.

\begin{tabular}{lccccc}
\hline $\begin{array}{l}\text { Crack } \\
\text { number }\end{array}$ & $\begin{array}{c}\text { Crack } \\
\text { type }\end{array}$ & $\begin{array}{c}\text { Crack } \\
\text { radius } \\
(\mathrm{mm})\end{array}$ & $\begin{array}{c}\text { Crack } \\
\text { depth } \\
(\mathrm{mm})\end{array}$ & $\begin{array}{c}\text { The angle of } \\
\text { the ring } \\
\text { crack arc } \\
\mathrm{AB}\left(^{\circ}\right)\end{array}$ & $\begin{array}{c}\text { Crack } \\
\text { initial } \\
\text { angle }\left(^{\circ}\right)\end{array}$ \\
\hline A & I & & & & 40 \\
B & I & 0.21 & 0.051 & 90 & 50 \\
C & I & & & & 60 \\
D & III & & & & 130 \\
E & III & 0.21 & 0.051 & 90 & 140 \\
F & III & & & & 150 \\
\hline
\end{tabular}

is that at this angle, the $K_{\mathrm{II}}$ of the crack is much larger than other initial angles. It is worth noting that both crack I and crack III achieve the maximum value of $K_{\mathrm{I}}$ when the initial crack angle makes the crack surface closest to the sphere.

Based on the analysis in Section 3, we believe that this phenomenon is related to the distance between the crack front and the bearing ball surface. For crack III, the larger the initial angle between the crack and the $X$-axis, the closer the crack front to the ball surface. Correspondingly, the larger the $K_{\mathrm{I}}$ and the smaller the $K_{\mathrm{II}}$, that is, the greater the influence of tensile stress on the crack front and the smaller the 


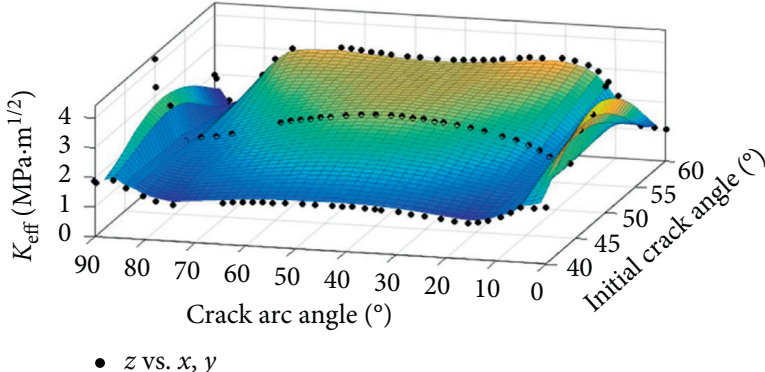

(a)

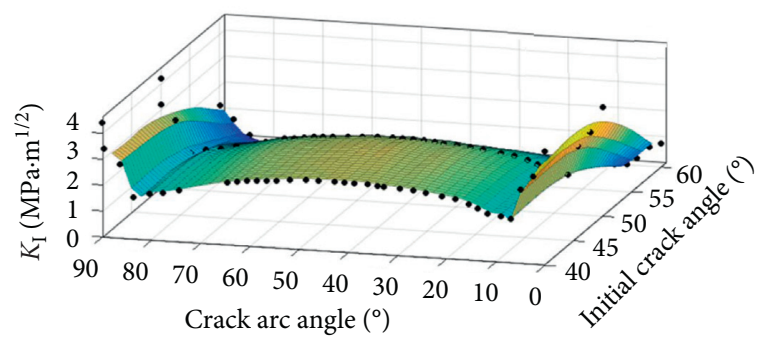

- $z$ vs. $x, y$

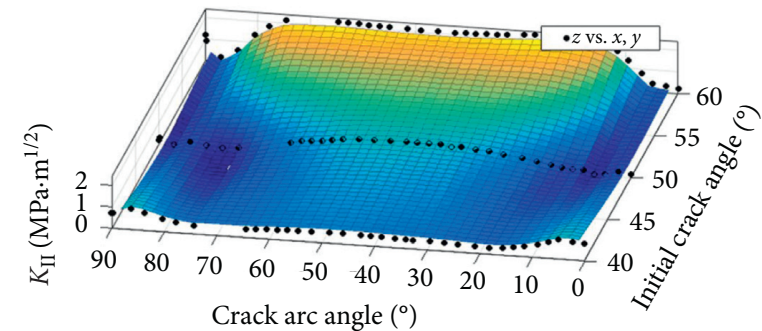

(c)

FIGURE 17: Calculation of the SIFs of crack I: (a) the calculation result of $K_{\text {eff }}$ for the crack I at different initial crack angles; (b) the calculation result of $K_{\mathrm{I}}$ for the crack I at different initial crack angles; (c) the calculation result of $K_{\mathrm{II}}$ for the crack I at different initial crack angles.

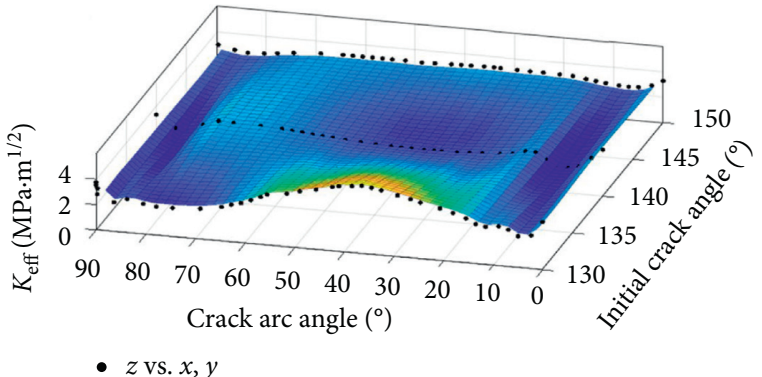

(a)

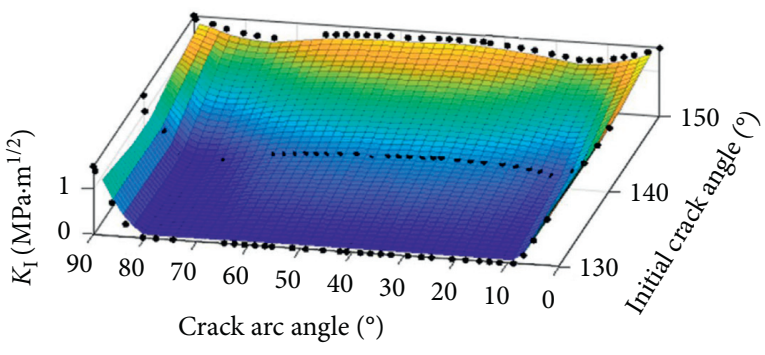

- $z$ vs. $x, y$

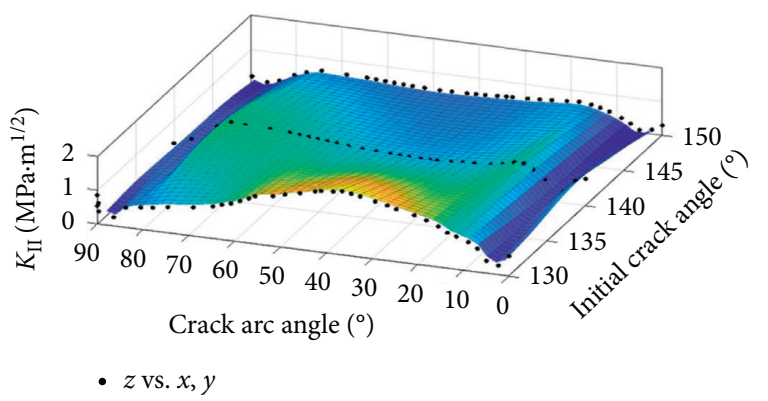

(c)

FIGURE 18: Calculation of the SIFs of crack III: (a) the calculation result of $K_{\text {eff }}$ for crack III at different initial crack angles; (b) the calculation result of $K_{\mathrm{I}}$ for crack III at different initial crack angles; (c) the calculation result of $K_{\mathrm{II}}$ for crack III at different initial crack angles.

influence of compressive stress on the crack front. For crack I, the smaller the initial angle between the crack and the positive $X$-axis, the closer the crack front is to the ball surface, and the corresponding force is the same as crack III. In actual engineering, crack propagation in mode I will cause low-stress brittle cracking of mechanical parts. Such cracks are considered to be the most dangerous cracks and should be avoided as much as possible. In summary, it can be known that crack propagation has a great relationship with the distance between the front of the crack and the surface of 
the bearing ball. When the distance between the crack and the surface of the bearing ball is short, try to avoid the use of the bearing ball.

\section{Conclusion}

The surface crack growth is analysed in detail, and the following conclusions can be drawn from the current research. It has been described that the initial crack angle and the load position have a great influence on the direction and mode of crack propagation. When the Hertzian contact load boundary just coincides with arc $\mathrm{AB}$, the initial crack is in the most dangerous position and the crack is the easiest to propagate. In addition, the SIFs are related to the initial crack angle. For crack I and II, the smaller the initial crack angle, the smaller the distance between the crack front and the bearing ball surface, and the easier the crack will grow in the form of mode I, and the larger the $K_{\mathrm{I}}$; the larger the initial crack angle, the greater the distance between the crack front and the bearing surface and the easier the crack to propagate in the form of mode II, the larger the $K_{\mathrm{II}}$, and the SIF calculation for crack III is the opposite to cracks I and II. The larger the initial crack angle, the larger the $K_{\mathrm{I}}$ and the smaller the $K_{\mathrm{II}}$. In general, this study clarified the influence of the initial angle and contact load of the crack in the silicon nitride ceramic bearing ball on the crack propagation.

\section{Data Availability}

The data used to support the findings of this study are included within the article.

\section{Conflicts of Interest}

The authors declare that there are no conflicts of interest regarding the publication of this paper.

\section{Acknowledgments}

This research was supported by the Key Laboratory of Vibration and Control of Aero-Propulsion System, Ministry of Education, Northeastern University (no. VCAME202106), and the National Science Foundation of China (grant nos. 52075348, 51905357, 52005352, and 51805337).

\section{References}

[1] S. Y. Geng, M. S. Yang, and K. Y. Zhao, "Fatigue crack initiation and propagation behavior of high cobalt molybdenum stainless bearing steel," Journal of Iron and Steel Research, vol. 30, no. 11, pp. 906-915, 2018.

[2] Y. J. Wang, M. S. Yang, S. Q. Sun, and Z. H. Zhang, "Fatigue crack formation and propagation behavior of 30Cr3WVE bearing steel," Journal of Iron and Steel Research, vol. 30, no. 3, pp. 213-221, 2018.

[3] H. Shi, Z. Liu, X. Bai, Y. Li, and Y. Wu, "A theoretical model with the effect of cracks in the local spalling of full ceramic ball bearings," Applied Sciences-Basel, vol. 9, no. 19, 2019.

[4] I. Khader, S. Rasche, T. Lube, R. Raga, U. Degenhardt, and A. Kailer, "Lifetime prediction of ceramic components-a case study on hybrid rolling contact," Engineering Fracture Mechanics, vol. 169, pp. 292-308, 2017.

[5] J. L. Zhou, Rolling Contact Fatigue Life of Silicon Nitride Ceramic Balls, Shanghai University, Shanghai, China, 2006.

[6] Y. Wang and M. Hadfield, "The influence of ring crack location on the rolling contact fatigue failure of lubricated silicon nitride: fracture mechanics analysis," Wear, vol. 243, pp. 167-174, 2000.

[7] T. Slack and F. Sadeghi, "Cohesive zone modeling of intergranular fatigue damage in rolling contacts," Tribology International, vol. 44, no. 7-8, pp. 797-804, 2011.

[8] A. Warhadpande and F. Sadeghi, "Effects of surface defects on rolling contact fatigue of heavily loaded lubricated contacts," Proceedings of the Institution of Mechanical Engineers, Part J: Journal of Engineering Tribology, vol. 224, no. 10, pp. 10611077, 2010.

[9] J. L. Zhou, G. Q. Wu, W. N. Zhu, and X. Y. Chen, "Tensile stress fatigue life model of silicon nitride ceramic balls," Tribology International, vol. 42, no. 11-12, pp. 1838-1845, 2009.

[10] B. Karunamurthy, M. Hadfield, C. Vieillard, G. E. MoralesEspejel, and Z. Khan, "Cavitation and rolling wear in silicon nitride,” Ceramics International, vol. 36, no. 4, pp. 1373-1381, 2010.

[11] S. Pattabhiraman, G. Levesque, N. H. Kim, and N. K. Arakere, "Uncertainty analysis for rolling contact fatigue failure probability of silicon nitride ball bearings," International Journal of Solids and Structures, vol. 47, no. 18-19, pp. 2543-2553, 2010.

[12] K. Kida, J. Koga, and E. C. Santos, "Crack growth and splitting failure of silicon nitride ceramic balls under cyclic pressure loads," Mechanics of Materials, vol. 106, pp. 58-66, 2017.

[13] S. Deng, L. Hua, X. Han, and S. Huang, "Investigation of rolling contact fatigue cracks in ball bearings," International Journal of Fracture, vol. 188, no. 1, pp. 71-78, 2014.

[14] D. Xu, Research on Residual Fatigue Life Analysis and Prediction of Ball Bearings, National University of Defense Technology, Changsha, China, 2011.

[15] D. Xu, Y. C. Xu, X. Chen, X. L. Li, and Y. M. Yang, "Fatigue life prediction of ball bearings by modified Paris law based on critical curved surface," Journal of Mechanical Engineering, vol. 47, no. 2, pp. 51-57, 2011.

[16] D. Xu, J. e. Huang, Q. Zhu, X. Chen, Y. Xu, and S. Wang, "Residual fatigue life prediction of ball bearings based on Paris law and RMS," Chinese Journal of Mechanical Engineering, vol. 25, no. 2, pp. 320-327, 2012.

[17] Z. Q. Wang, Z. J. Yang, and L. Q. Tang, "A new yield criterion for analysis of ceramic phase transformation toughening law based on critical curved surface," Journal of Harbin Engineering University, vol. 32, no. 1, pp. 21-25, 2011.

[18] H. Shi, Y. Li, X. Bai et al., "Investigation of the orbit-spinning behaviors of the outer ring in a full ceramic ball bearing-steel pedestal system in wide temperature ranges," Mechanical Systems and Signal Processing, vol. 149, 2021.

[19] L. M. Keer and M. D. Bryant, "A pitting model for rolling contact," Journal of Lubrication Technology, vol. 105, no. 2, p. 198, 1983.

[20] S. D. Sheppard, "Discussion: "the influence of crack face friction and trapped fluid on surface initiated rolling contact fatigue cracks" (Bower, A. F., 1988, ASME J. Tribol., 110, pp. 704-711)," Journal of Tribology, vol. 111, no. 2, pp. 515-520, 1989.

[21] Y. Wang and M. Hadfield, "Failure modes of ceramic rolling elements with surface crack defects," Wear, vol. 256, no. 1-2, pp. 208-219, 2004. 
[22] M. T. Hanson and L. M. Keer, "An analytical life prediction model for the crack propagation occurring in contact fatigue failure," Tribology Transactions, vol. 35, no. 3, pp. 451-461, 1992.

[23] M. Kaneta, M. Suetsugu, and Y. Murakami, "Mechanism of surface crack growth in lubricated rolling/sliding spherical contact," Journal of Applied Mechanics, vol. 53, no. 2, pp. 377-390, 1986.

[24] Y. Murakami, M. Kaneta, and H. Yatsuzuka, "Analysis of surface crack propagation in lubricated rolling contact," ASLE Transactions, vol. 28, no. 1, pp. 60-68, 1985.

[25] Y. Murakami, C. Sakae, and K. Ichimaru, "Three-dimensional fracture mechanics analysis of pit formation mechanism under lubricated rolling-sliding contact loading," STLE Tribology Transactions, vol. 37, 1994.

[26] H. Riesch-Oppermann, S. Scherrer-Rudiy, M. Härtelt, and O Kraft, "Reliability prediction for contact strength and fatigue of silicon nitride high strength components using an R-curve approach," Engineering Fracture Mechanics, vol. 100, pp. 52-62, 2013.

[27] M. H. Nazir, Z. A. Khan, and A. Saeed, "Experimental analysis and modelling of c-crack propagation in silicon nitride ball bearing element under rolling contact fatigue," Tribology International, vol. 126, pp. 386-401, 2018.

[28] L. Hua, S. Deng, X. Han, and S. Huang, "Effect of material defects on crack initiation under rolling contact fatigue in a bearing ring," Tribology International, vol. 66, pp. 315-323, 2013.

[29] C. Vieillard, "Observation of subsurface rolling contact fatigue cracks in silicon nitride and comparison of their location to Hertzian contact subsurface stresses," International Journal of Fatigue, vol. 96, pp. 283-292, 2017.

[30] Q. P. Zhong, Crackology, Higher Education Press, Beijing, China, 2014. 